\title{
Acidente Vascular Cerebral Isquémico: Estender a Terapêutica Específica de Fase Aguda ao Maior Número de Doentes e Estimar o Benefício Individual
}

\author{
Ischemic Stroke: Increasing the Number of Patients \\ Submitted to Acute Specific Therapy and Estimating the \\ Individual Benefits
}

Miguel VIANA-BAPTISTA $\triangle^{1,2}$

Acta Med Port 2016 Nov;29(11):683-683 - http://dx.doi.org/10.20344/amp.8367

Palavras-chave: Acidente Vascular Cerebral/tratamento; Terapêutica Trombolítica; Trombectomia

Keywords: Stroke/therapy; Thrombectomy; Thrombolytic Therapy.

O tratamento de fase aguda do acidente vascular cerebral isquémico conheceu importantes avanços nos últimos anos. À terapêutica trombolítica intravenosa com alteplase, aprovada pela primeira vez nos Estados Unidos da América há vinte anos atrás e posteriormente introduzida na Europa, veio recentemente juntar-se a terapêutica endovascular para os doentes com oclusão proximal de um grande vaso intracraniano, condicionando uma restruturação organizacional importante face à actual exiguidade de recursos humanos e técnicos necessários para implementar a trombectomia. Quer numa situação quer na outra, os investigadores dedicaram particular atenção à selecção de doentes, na tentativa de garantir a segurança dos mesmos e de demonstrar a eficácia da terapêutica. Sem surpresa, o intervalo de tempo desde a instalação dos sintomas e o início do tratamento emergiu como um dos factores determinantes do sucesso da terapêutica. Na transposição destes dados para a prática clínica, os profissionais de saúde têm vindo a centrar os seus esforços na organização intra-hospitalar, reforçando a noção de emergência e procurando fazer chegar a terapêutica de fase aguda a um número crescente de doentes. Acontece que, mesmo reconhecendo o enorme avanço na terapêutica específica do acidente vascular cerebral isquémico, uma meta-análise de oito ensaios, publicada em $2015,{ }^{1}$ mostrou que mais de metade dos doentes tratados com trombectomia se encontravam dependentes aos três meses (modified Rankin Scale > 2), pelo que é necessário ter presente que o tratamento não se resume à fase aguda mas implica um contínuo de cuidados no qual a reabilitação tem um papel indispensável.

A identificação de preditores de compromisso funcional na fase aguda do acidente vascular cerebral isquémico tendo em vista a definição de um programa de reabilitação

\section{REFERÊNCIAS}

1. Badhiwala JH, Nassiri F, Alhazzani W, Selim MH, Farrokhyar F, Spears $\mathrm{J}$, et al. Endovascular thrombectomy for acute ischemic stroke: a metaanalysis. JAMA. 2015;314:1832-43. surge como uma necessidade não preenchida, sendo que, até à data, como sublinha o trabalho publicado por João Paulo Branco et al neste número da Acta Médica Portuguesa, ${ }^{2}$ não foi possível validar um modelo preditivo aplicável nas primeiras horas mesmo utilizando marcadores imagiológicos ou laboratoriais. Assim, é necessário prosseguir a investigação no sentido de melhor delinear os programas de reabilitação. Tratando-se de um trabalho de revisão, o artigo supracitado tem o mérito de, ao contribuir para uma melhor interpretação dos dados disponíveis na literatura, deslocar o enfoque no sentido da reabilitação, sublinhando que os esforços da comunidade médica e a atenção dos decisores políticos não podem restringir-se a proporcionar uma terapêutica de fase aguda a todos os que dela necessitam mas devem estender-se a fazer chegar o tratamento de reabilitação de forma generalizada na justa medida das necessidades de cada um. Neste particular, a introdução da trombectomia veio ainda aumentar mais o número de variáveis passíveis de influenciar o prognóstico, sublinhando a importância da avaliação clínica e intervenção precoce da Medicina Física e de Reabilitação no tratamento do doente com acidente vascular cerebral isquémico. No futuro, espera-se que a identificação durante a fase aguda de preditores de compromisso funcional possa contribuir para uma melhor avaliação das reais necessidades de cada doente e para a utilização criteriosa dos recursos de reabilitação.

\section{CONFLITOS DE INTERESSE}

O autor declara ter recebido honorários por serviços de consultoria e palestras científicas, bem como apoio para deslocação a reuniões científicas da Boehringer Ingelheim, Portugal.

2. Branco JP, Costa JS, Sargento-Freitas J, Oliveira S, Mendes B, Laíns J, et al. Neuroimaging and blood biomarkers in functional prognosis after stroke. Acta Med Port. 2016;29:749-754.

1. Serviço de Neurologia. Hospital Egas Moniz. Centro Hospitalar de Lisboa Ocidental. Lisboa. Portugal.

2. CEDOC - iNOVA4Health. Faculdade de Ciências Médicas. Universidade Nova de Lisboa. Lisboa. Portugal.

$\triangle$ Autor correspondente: Miguel Viana-Baptista. mvianabaptista@fcm.unl.pt

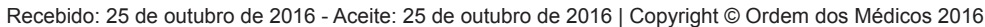

